\title{
Analisis Budaya Organisasional dan Konflik Peran terhadap Kepuasan Kerja dan Komitmen Organisasi (Studi pada Kantor Akuntan Publik)
}

\author{
Soni Agus Irwandi \\ Jurusan Akuntansi STIE Perbanas Surabaya \\ Jalan Nginden Semolo 34-36 Surabaya 60118 \\ Email:soni_irwandi@perbanas.ac.id
}

\begin{abstract}
This study is an extension of the study of Aranya et.al (1994) which try to determine the influence of organizational culture on job satisfaction and organizational commitment, the effect of role conflict on job satisfaction and organizational commitment in Indonesia. This is a survey research. 500 questionnaire was sent to public accountant staff in Java and South Sulawesi. The result show that organizational culture influence significantly on job satisfaction organizational commitment.
\end{abstract}

Keywords: organizational culture, role conflict, organizational commitment

\section{PENDAHULUAN}

Kepuasan kerja merupakan salah satu faktor penting yang mempengaruhi kepuasan hidup karena sebagian besar waktu manusia dihabiskan di tempat kerja (Riggio,1990). Studi mengenai kepuasan kerja dan komitmen organisasi merupakan topik yang menarik dan dapat dijadikan pertimbangan saat mengkaji model pergantian akuntan yang bekerja di Kantor Akuntan Publik (KAP). Menurut Gregson (1992) kepuasan kerja adalah sebagai pertanda awal komitmen organisasi dalam sebuah pergantian akuntan yang bekerja di KAP.

Dalam studi lain yang berkaitan, Aranya et.al. (1982) menganalisis efek komitmen organisasional dan profesional pada kepuasan kerja para akuntan yang diperkerjakan. Dengan menggunakan komitmen organisasi dan komitmen profesional sebagai prediktor kepuasan kerja. Mereka melaporkan adanya suatu korelasi nyata secara statistik antara komitmen organisasional dan kepuasan kerja.

Suwandi dan Indriantoro (1992) menemukan hasil yang konsisten dengan penelitian sebelumnya yaitu kepuasan kerja berkorelasi positif dengan komitmen organisasional. Bukti empiris lain menunjukkan adanya ketidakjelasan hubungan antara kepuasan kerja dengan peningkatan komitmen organisasi. Penelitian yang menguji hubungan antara kedua variabel tersebut menunjukkan hasil yang tidak konsisten.

Mathieu \& Zajac (1990) menyatakan bahwa kepuasan kerja merupakan variabel yang mendahului komitmen organisasi dan Bateman dan Strasser (1984) mendukung hipotesa tersebut yaitu komitmen organisasi mendahului kepuasan kerja. Tetapi studi terbaru mengenai urutan kausal kedua variabel menemukan bahwa komitmen organisasi dan kepuasan kerja berhubungan secara resiprokal,

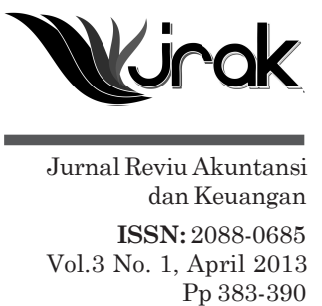


Analisis

Budaya

Organisasional

392 tanpa ada yang mempengaruhi variabel lainnya secara lebih kuat (Mathieu, 1991). Oleh karena itu penel itian yang menguji hubungan tingkat kepuasan kerja dalam peningkatan komitmen organsasi merupakan satu topik yang menarik dan banyak kegunaannya dalam penelitian-penel itian bidang akuntansi keprilakuan Poznanski et al., (1997). Hal ini juga yang menjadi alasan peneliti untuk memilih topik penelitian ini dan menguji kembali hubungan antara kepuasan kerja dengan komitmen organisasional. Tetapi dalam penelitian ini tidak menguji hubungan kepuasan kerja dengan komitmen organisasi melainkan menguji variabel-variabel yang diperkirakan berpengaruh terhadap kepuasan kerja dan komitmen organisasi.

Menurut Davis (1995) kepuasan kerja adalah perasaan menyokong atau tidak menyokongyang dialami pegawai dalam bekerja. kepuasan kerja adalah cara pegawai merasakan dirinya atau pekerjaannya. Menurut Mangkunegara (2000) kepuasan kerja adalah suatu perasaan yang menyokong atau tidak menyokong diri pegawai yang berhubungan dengan pekerjaannya maupun dengan kondisi dirinya. Perasaan yang berhubungan dengan pekerjaan yang mel ibatkan aspek-aspek seperti upah atau gaji yang diterima, kesempatan pengembangan karir, hubungan dengan pegawai lainnya, penempatan kerja, jenis pekerjaan, struktur organisasi, mutu pengawasan, kondisi kesehatan, kemampuan, dan pendidikan. Pegawai akan merasa puas dal am bekerja apabi la aspek-aspek pekerjaan dan aspek-aspek dirinya menyokong dan sebaliknya jika aspek-aspek tersebut tidak menyokong, pegawai akan merasa tidak puas.

Sejalan dengan faktor-faktor yang mempengaruhi hubungan kepuasan kerja dengan komitmen organisasi, budaya organisasional dan konflik peran diduga dapat mempengaruhi hubungan kepuasan kerja dengan komitmen organisasi. Hasil peneliti terdahulu yang berkaitan budaya organisasi dengan komitmen organisasi dan kepuasan kerja sebagai antesedent dengan menggunakan H ofstede's Value Survey (MSM) menunjukkan hasil yang signifikan. Hasil studi Kozlowski \& Doherty (1989) yang dikutip dari studi O’Driscoll \& Beehr (1994) menunjukkan bahwa bagian dari elemen organisasi di KAP yaitu supervisor merupakan pihak yang paling dekat dengan konteks kerja seseorang karena melalui mereka tercermin budaya dan iklim organisasi. Hasil studi ini didukung oleh O'Driscoll et al. (1992) yang menunjukkan bahwa stress karena peran dan ketidakpastian dalam konteks pekerjaan akan menyebabkan ketidakpuasan kerja yang pada akhirnya akan meningkatkan ketegangan, mengurangi komitmen organisasi dan meningkatkan kecenderungan untuk berpindah.

Konflik peran yang merupakan suatu gejala psikologis yang dialami oleh anggota organisasi yang bi sa menimbulkan rasa tidak nyaman dalam bekerja dan secara potensial bisa menurunkan motivasi kerja Fitria dan Riyanto (1999). Menurut Kahn et.al. (1964) dan J ackson dan Shuler (1985) bahwa konflik peran mempunyai dampak yang negatif terhadap perilaku karyawan, seperti timbul nya ketegangan kerja, peningkatan perputaran kerja, penurunan kepuasan kerja, penurunan komitmen organisasi dan penurunan kinerja keseluruhan. Oleh karena itu penelitian ini menguji lagi secara empiris sejauh mana budaya organisasional dan konflik peran berpengaruh terhadap kepuasan kerja. Tujuan dari penelitian ini ingin melihat budaya organisasional memberikan pengaruh yang signifikan terhadap kepuasan kerja dan komitmen organisasional. dan konflik peran memberikan pengaruh yang signifikan terhadap kepuasan kerja dan komitmen organisasional.

\section{Pengembangan Hipotesis}

Budaya telah didefinisikan dengan berbagai cara, namun belum dapat ditentukan definisinya secara pasti Ouchi \& Wilkins, (1985). Budaya merupakan normanorma dan nilai-nilai yang mengarahkan perilaku anggota organisasi Luthan, (1998). Setiap anggota akan berperilaku sesuai dengan budaya yang berlaku agar diterima di lingkungannya. 
Menurut Reynolds. (1986) praktek-praktek yang di lakukan oleh anggota suatu budaya juga perlu diamati karena mereka mengambarkan manifestasi dari nilainilai budaya tersebut. H ofstede et. al. (1990) menyatakan bahwa "nilai-nilai yang dimanifestasikan dalam ber bagai pilihan perilaku". Mereka juga membuktikan, walaupun nilai-nilai dan praktek budaya adalah faktor-faktor yang penting, tetapi faktor yang lebih penting dalam menjelaskan perbedaan diberbagai organisasi adalah persepsi yang dianut dalam praktek sehari-hari. Maka dari itu, untuk memahami nilai-nilai yang dianut serta memahami praktek-praktek yang merupakan manifestasi dari nilai-nilai tersebut.

Lebih lanjut menurut Hofstede et.al (1990) dua jenis praktek organisasi, yang ditimbulkan ol eh, serta menghasilkan nilai-nilai budaya adalah proses seleksi dan proses sosialisasi. Proses seleksi terdiri dari dua komponen yaitu perekrutan dan seleksi individu. Perekrutan adalah cara mengindentifikasi, menyaring dan mengundang orang luar untuk masuk menjadi bagian unit budaya. Untuk itu perlu di cari individu-individu yang memiliki nilai-nilai budaya yang serupa dengan nilai-nilai yang dianut ol eh anggota kel ompok. Sedangkan sel eksi indi vidu adalah proses penyesuaian yang dilakukan oleh orang luar agar dirinya dapat direkrut. Tiap-tiap individu cenderung untuk mencari dan memilih sistem budaya yang sesuai dengan nilai-nilai personel mereka.

$\mathrm{Hla}$ : Faktor budaya organisasional secara signifikan memberikan pengaruh positif terhadap kepuasan kerja.

$\mathrm{HIb}$ : Faktor budaya organisasional secara signifikan memberikan pengaruh positif terhadap komitmen organisasi.

Dalam linkungan kerja akuntan publik, konflik peran berhubungan dengan adanya dua rangkaian tuntutan yang bertentangan. Tanpa pengetahuan tentang struktur audit yang baku, staf akuntan mempunyai kecenderungan mengalami kesulitan dal am menjal ankan tugasnya. Kesulitan ini timbul sehubungan dengan beberapa faktor yang terindentifikasi dalam studi Bamber et. al. (1989) seperti koordinasi arus kerja, kecukupan wewenang, kecukupan komunikasi dan kemampuan adaptasi.

Menurut Suwandi dan Indriantoro (1999) Koordinasi aruskerja menyangkut seberapa baik ber bagai aktivitas kerja yang sal ing berhubungan dapat dikoordinasi dan seberapa jauh individu mendapat informasi tentang kemajuan tugasnya. Kecukupan wewenang berhubungan dengan sejauh mana individu mempunyai wewenang untuk mengambil keputusan yang perlu dan mengatasi masalah kerja. Kecukupan komunikasi berhubungan dengan derajat penyediaan informasi yang akurat dan tepat waktu sesuai kebutuhan. Kemampuan adaptasi mengacu pada kemampuan untuk menangani perubahan keadaan dengan baik dan tepat waktu. Sedangkan tanpa ada struktur yang baku dapat dicontohkan dalam bentuk formulasi aturan dan prosedur yang komprehensif, maka auditor senior berperan sangat penting dal am mengawasi pekerjaan staf akuntan dan memberikan bantuan yang diperlukan. Kelemahan pengawasan ol eh auditor senior akan berakibat staf akuntan harus mengerjakan tugasnya tanpa pedoman sehingga lebih cenderung menghadapi konflik peran, terutama antara tuntutan audit dan tuntutan klien.

Menurut Puspa dan Riyanto (1999) konflik peran merupakan suatu gejala psikol ogis yang dialami oleh anggota organisasi yang bisa menimbulkan rasa tidak nyaman dalam bekerja dan secara pontensial akan menurunkan motivasi

kerja. Kahn et. al. (1964) dan J ackson dan Shuler (1985) menemukan bahwa konflik peran mempunyai dampak yang negatif terhadap perilaku karyawan, seperti timbulnya ketegangan kerja, penurunan komitmen pada organisasi dan penurunan kinerja keseluruhan.

$\mathrm{H} 2 \mathrm{a}$ : Faktor konflik peran secara signifikan memberikan pengaruh negatif terhadap kepuasan kerja. 
Analisis

Budaya

Organisasional

394
$\mathrm{H} 2 \mathrm{~b}$ : Faktor konflik peran secara signifikan memberikan pengaruh negatif ter hadap komitmen organisasional.

\section{METODE}

Penelitian ini menggunakan staf akuntan publik secara individual sebagai unit yang dianalisis. Peneliti mengumpulkan data penelitian dengan mengirimkan kuisioner kepada 500 orang staf akuntan publik yang ada di Indonesia. Data dan alamat diambil dari direktori Kantor Akuntan Publik Tahun 2008 yang diterbitkan oleh I katan Akuntan Indonesia (IAI) Kompartemen Akuntan Publik sebagai rerangka sampling.

\section{Operasional Variabel}

Kepuasan kerja.

Kepuasan kerja yang dimaksud dalam penelitian ini adalah tingkat kepuasan kerja indi vidu staff akuntan yang bekerja pada kantor akuntan publik (KAP). Untuk mengukur variabel kepuasan kerja, peneliti menggunakan instrumen The Minnesota Satisfaction Quetionare (MSQ/ kuesioner kepuasan Minnesota) yang dikembangkan untuk menghubungkan penilaian dengan teori. Weiss \& Marvin et. al. (1972) melaporkan validitas konsep berdasarkan hasil pengujian isntrumen ini dalam profesi yang sama dan antara profesi yang berbeda. Hasilnya adalah koefisien internal umum sebesar 0,90 Weiss et. al (1967). Alasan peneliti menggunakan instrumen ini adalah pertama, Dunham et. al (1997) menemukan bahwa pengukuran ini menghasilkan covergent validity tertinggi dibandingkan dengan pengukuran lainnya. Kedua MSQ lebih komprehensif mengukur segi-segi spesifik dari kepuasan kerja. Dan terakhir, Scarpello \& Campbell. (1983) menyatakan bahwa MSQ memiliki kemampuan lebih baik dalam mempredi ksi kepuasan kerja dari pada instrumen lainnya. Peneliti lain yang menggunakan instrumen ini adalah Poznanski dan Bline (1997) untuk menguji hubungan sebab akibat kepuasan kerja dengan komitmen organisasional.Setiap responden diminta untuk menjawab 20 butir pertanyaan dengan menggunakan skala kategori (Category Scale) yang berkaitan kepuasan dengan 5 (lima) pilihan yaitu (1) Sangat Memuaskan, (2) Memuaskan, (3) Sedang, (4) Kurang Memuaskan, (5) Sangat Memuaskan.

Komitmen Organisasional.

Komitmen organisasional dalam penelitian ini diukur dengan menggunakan Organizational Comitment Questionare (OCT) yang dikembangkan oleh Porter. et. al (1974). Dengan kuesiner ini bermacam analisis dilaksanakan dengan menggunakan sampel yang berbeda Mowday \& Porter. (1979). Dengan menggunakan skala likert (Likert Scale) 1 sampai 5 yaitu (1) sangat setuju,(2) setuju, (3) tidak pasti atau neutral, (4) tidak setuju dan (5) sangat tidak setuju. Setiap responden diminta untuk menjawab 15 item pertanyaan dan untuk kata "organisasi" peneliti menggantinya dengan "KAP". Peneliti lain yang menggunakan instrumen ini adalah Suwandi dan Indriantoro (1999) untuk mengukur komitmen organisasi di lingkungan kantor akuntan publik di Indonesia dan Poznanski et all. (1997) untuk menguji hubungan sebab akibat kepuasan kerja dengan komitmen organisasi.

Budaya Organisasional.

Budaya organisasional yang dimaksud dalam penelitian ini menggunakan dimensi praktek, yaitu nilai-nilai dan keyakinan (belief) yang dimiliki oleh 
para staf akuntan, yang dimanifestasikan dalam bentuk norma - norma perilaku para individu atau kel ompok organisasi yang bersangkutan (H ofstede \& Geert, 1990; Kotter dan Heskett, 1992). Variabel kultur organisasi dimaksudkan secara spesifik untuk menjelaskan orientasi kultur perusahaan pada level depertemen atau bagian. variabel ini diukur dengan instrumen yang dikembangkan oleh peneliti berdasarkan hasil analisis faktor pada instrumen H ofstede \& Geert (1990). Analisis faktor memuat skor rata-rata unit sebagai indikator kunci dimensi kultur organisasional, terutama faktor-faktor yang mempunyai bobot skor rata-rata diatas 0,60.

Pengembangan instrumen dengan sedikit modifikasi di lakukan peneliti setelah tidak berhasil memperol eh instrumen kultur organisasional yang dibuat dan digunakan oleh H ofstede \& Geert (1990) dengan menggunakan skala Likert lima point. Setiap butir pertanyaan dimulai kalimat "ditempat saya bekerja" (where I work). peneliti membuat modifikasi instrumen sebagai berikut: (1) setiap item kuisioner berisi pertanyaan mengenai dimensi kultur organisasional yang mempertentangkan antara orientasi pada orang dengan orientasi pada pekerjaan, (2) pilihan jawaban meliputi angka satu sampai dengan lima yang menunjukkan rendah untuk kultiur yang berorientasi pada orang dan skala tinggi untuk kultur yang berorientasi pada pekerjaan. Peneliti lain yang menggunakan instrumen ini adalah Supomo dan Indriantoro (1998) meli hat pengaruh budaya organisasi terhadap hubungan anggaran partisipatif dengan kinerja manajerial, pengaruh anggaran partisipatif terhadap job satisfaction dan job performance dengan budaya organisasi dan locus of control sebagai variabel moderating dan penelitian yang sama untuk melihat budaya organisasi di kantor akuntan publik adalah Pratt \& Beaulieu (1992).

\section{Konflik Peran.}

Konflik peran diukur dengan menggunakan instrumen yang dikembangkan oleh Rizzo et. al (1970). Instrumen ini terdiri delapan item dengan skala lima poin seperti "saya bekerja dibawah kebijakan aturan yang saling bertentangan", poin rendah menandakan tingkat konflik peran yang dihadapi individu rendah dan sebaliknya poin tinggi menandakan tingkat konflik yang dihadapi tinggi. Koefisien Cronbach alpha untuk instrumen ini 0,85.

\section{Teknik Analisis dan Uji Hipotesis.}

Uji Kualitas Data (Instrumen).

Menurut Huck dan Cormier (1996), kual itas data yang dihasilkan dari penggunaan instrumen penelitian dapat dievaluasi melalui uji Reliabilitas dan validitas. Uji tersebut masing-masing untuk mengetahui konsistensi dan akurasi data yang dikumpulkan dari penggunaan instrumen. Ada tiga prosedur yang di lakukan dalam penelitian ini untuk mengukur reliabilitas dan validitas data, yaitu:

1) Uji konsistensi internal dengan koefisien (Cronbach) al pha

2) Uji homogenitas data dengan uji korelasional antara skor masing-masing butir dengan total.

\section{Uji Hipotesis.}

Metode statistik yang digunakan untuk menguji hipotesis adalah regresi berganda (Multiple regression). Sesuai dengan rumusan masalah, tujuan, dan hipotesis penelitian ini, metode regresi berganda menghubungkan satu variabel dependen dengan beberapa variabel independen dalam suatu model prediktif tunggal. Model yang digunakan dalam penelitian ini disajikan dalam gambar berikut ini:

Dalam hal ini: 
Budaya

Organisasional

396
Tabel 1.

Hasil Ujian

Reliabilitas Pengaruh

Budaya Organisasi

dan Konflik Peran,

Terhadap Kepuasan

Kerja, dan

Komitmen

Organisasi
Tabel 2.

Hasil Uji

Kor elasional Pengaruh Budaya

Organisasi, dan

Konflik Peran,

Terhadap Kepuasan

Kerja dan komitmen Organisasi.

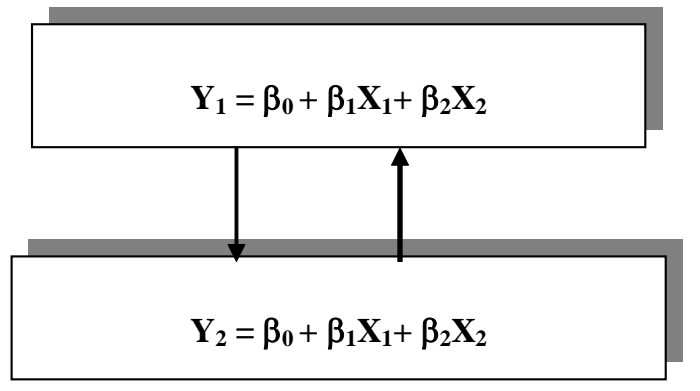

$Y_{1}=$ Kepuasan Kerja diukur berdasarkan penjumlahan skor setiap butir.

$Y_{2}=$ Komitmen Organisasi diukur berdasarkan penjumlahan skor setiap butir.

$\mathrm{X}_{1}$ = Budaya Organisasi diukur berdasarkan penjumlahan skor yang telah distandarisasi.

$\mathrm{X}_{2}=$ Konflik Peran diukur berdasarkan penjumlahan skor yang telah distandarisasi.

\section{HASIL DAN PEMBAHASAN}

\section{Pengujian Kualitas Data \\ Uji Reliabilitas}

Pernyataan-pernyataan yang tidak valid dikeluarkan, selanjutnya dilakukan tes reliabilitas. Tes ini dimaksudkan untuk menentukan tingkat kepercayaan minimal yang dapat diberikan terhadap kesungguhan jawaban yang diterima. Pendekatan yang digunakan adalah menggunakan indeks koefisien alpha dari Cronbach Alpha. Hasilnya ditunjukkan pada tabel.dan Iampiran hasil /output yang disertakan.

\begin{tabular}{lc}
\hline \multicolumn{1}{c}{ Variabel } & Koefisien Alpha \\
\hline Kepuasan Kerja $\left(\mathrm{Y}_{1}\right)$ & 0,8004 \\
Komitmen Organisasi $\left(\mathrm{Y}_{2)}\right.$ & 0,6216 \\
Budaya Organisasi $\left(\mathrm{X}_{1}\right)$ & 0,6274 \\
Konflik Peran $\left(\mathrm{X}_{2}\right)$ & 0,7362 \\
\hline
\end{tabular}

Tabel 1 diatas menunjukkan bahwa koefisien reliabilitas (Cronbach Alpha) variabel kepuasan kerja 0,8004, artinya 80,04 \% alat pengukur kepuasan kerja dalam penelitian ini dapat dipercaya atau teruji. Koefisien reliabilitas komitman organisasi 0,6216 , artinya $62,16 \%$ alat pengukur komitmen organisasi dapat dipercaya atau teruji. Koefisien reliabilitas budaya organisasi 0,6274, artinya 62,74 $\%$ alat pengukur budaya organisasi dapat dipercaya atau teruji. Dan koefisien reliabilitas konflik peran 0,7362 , artinya $73,62 \%$ alat pengukur konflik peran dapat dipercaya atau teruji.

\section{Uji Korelasional.}

\begin{tabular}{ccccc}
\hline & Y1 & Y2 & X1 & X2 \\
\hline Y1 & $\mathbf{1 , 0 0 0}$ & 0,024 & $0,512^{*}$ & 0,092 \\
Y2 & 0,024 & $\mathbf{1 , 0 0 0}$ & 0,318 & $0,538^{*}$ \\
$\mathbf{X 1}$ & $0,512^{*}$ & 0,318 & $\mathbf{1 , 0 0 0}$ & 0,332 \\
$\mathbf{X 2}$ & 0,092 & $0,538^{*}$ & 0,332 & $\mathbf{1 , 0 0 0}$ \\
\hline
\end{tabular}


a. Pada Variabel Dependent $Y_{1}$ Terhadap Variabel $X_{1}$, dan $X_{2}$.

- Besarnya keeratan hubungan antara variabel kepuasan kerja $\left(Y_{1}\right)$, dengan budaya organisasi $\left(\mathrm{X}_{1}\right)$ dengan koefisien korelasinya adalah 0,512 . Sedangkan variabel kepuasan kerja $\left(Y_{1}\right)$ dengan variabel konflik peran $\left(X_{2}\right)$ koefisien korelasinya 0,092, dan variabel kepuasan kerja $\left(Y_{1}\right)$ dengan variabel komitmen organisasi $\left(\mathrm{Y}_{2}\right)$ koefisien korelasinya 0,024. Secara teoritis, karena korelasi antara variabel kepuasan kerja $\left(Y_{1}\right)$ dan budaya organisasi $\left(X_{1}\right)$ lebih besar $(>)$ dari variabel $Y_{1}$ dengan $\left(X_{2}\right)$.

- $\quad$ "Berarti variabel budaya organisasi $\left(X_{1}\right)$ lebih berpengaruh kuat terhadap kepuasan kerja $\left(\mathrm{Y}_{1}\right)$. Daripada hubungan kepuasan kerja $\left(\mathrm{Y}_{1}\right)$ terhadap variabel konflik peran $\left(\mathrm{X}_{2}\right)$, dan komitmen organisasi $\left(\mathrm{Y}_{2}\right)^{\prime \prime}$.

- Pengaruh yang lemah antara variabel budaya $(X 1)$ dengan konflik peran $\left(\mathrm{X}_{2}\right)$, yaitu 0,332 . Hal ini menandakan tidak ada multikolinieritas, atau tidak ada korelasi diantara variabel bebas.

b. Pada Variabel Dependent $\mathrm{Y}_{2}$ Terhadap Variabel $\mathrm{X}_{1}$, dan $\mathrm{X}_{2}$.

- Besarnya keeratan hubungan antara variabel komitmen organisasi $\left(Y_{2}\right)$, dengan budaya organisasi $\left(\mathrm{X}_{1}\right)$ dengan koefisien korelasi adalah 0,318 , sedangkan variabel komitmen organisasi $\left(Y_{2}\right)$ terhadap konflik peran $\left(X_{2}\right)$ koefisien korelasinya 0,538. Dan variabel komitmen organisasi $\left(Y_{2}\right)$ terhadap variabel kepuasan kerja $\left(Y_{1}\right)$ koefisien korelasinya 0,024. Secara teoritis, karena korelasi antara variabel komitmen organisasi $\left(\mathrm{Y}_{2}\right)$ dan variabel konflik peran $\left(X_{2}\right)$. lebih besar $(>)$ dibanding variabel $\left(Y_{1}\right)$ dengan $\left(\mathrm{X}_{1}\right)$.

- $\quad$ "Berarti konflik peran $\left(\mathrm{X}_{2}\right)$ lebih berpengaruh kuat terhadap komitmen organisasi $\left(Y_{2}\right)$. Daripada hubungan budaya organisasi $\left(X_{1}\right)$ dengan komitmen organisasi $\left(Y_{2}\right)$ terhadap variabel budaya organisasi $\left(X_{1}\right)$, dan kepuasan kerja $\left(\mathrm{Y}_{1}\right)^{\prime \prime}$.

- Pengaruh hubungan yang lemah antara variabel budaya $\left(X_{1}\right)$ dengan konflik peran $\left(\mathrm{X}_{2}\right)$, yaitu 0,332 . Hal ini menandakan tidak ada multikolinieritas, atau tidak ada korelasi diantara variabel bebas.

\section{Uji Statistik Deskriptif.}

a. Nilai rata-rata dalam variabel komitmen organisasi $\left(\mathrm{Y}_{2}\right)$ pada lampiran (Dengan jumlah data 52) adalah 45,00 dengan nilai tengah (range) adalah 20 dengan standar deviasi 5,10.

b. Nilai rata-rata dalam variabel kepuasan kerja $\left(\mathrm{Y}_{1}\right)$ pada lampiran (Dengan jumlah data 52) adalah 45,90 dengan nilai tengah (range) adalah 31 dengan standar deviasi 5,81.

C. Nilai rata-rata dal am variabel budaya organisasi $\left(X_{1}\right)$ pada lampiran (Dengan jumlah data 52) adalah 45,90 dengan nilai tengah (range) adalah 18 dengan standar deviasi 3,65.

d. Nilai rata-rata dalam variabel konflik peran $\left(\mathrm{X}_{2}\right)$ pada lampiran (Dengan jumlah data 52) adalah 45,00 dengan nilai tengah (range) adalah 13 dengan standar deviasi 3,67.

\section{Uji Hipotesa.}

\begin{tabular}{ccccc}
\hline Hipotesis & $\begin{array}{c}\text { Variabel } \\
\text { Dependent }\end{array}$ & Nilai t & Nilai Signifikansi & Status \\
\hline $\mathrm{H} 1 \mathrm{a}$ & $\mathrm{X} 1$ & 4,177 & 0,000 & Ditolak \\
$\mathrm{H} 1 \mathrm{~b}$ & $\mathrm{X} 2$ & $-0,675$ & 0,503 & Diterima \\
\hline
\end{tabular}

Tabel 3.

Uji Hipotesa Pada Variabel Dependent $Y_{1}$ Terhadap Variabel $X_{1}$, dan $X_{2}$. 
Analisis

Budaya

Organisasional

398

Tabel 4.

Uji Hipotesa Pada

Variabel Dependent

$Y_{2}$ Terhadap Variabel

$\mathrm{X}_{1}$, dan $\mathrm{X}_{2}$. a. Uji Hipotesa Pada Variabel Dependent $Y_{1}$ Terhadap Variabel $X_{1}$, dan $X_{2}$. J ika Statistik t hitung <Statistik t tabel, maka Ha diterima.

$\mathrm{J}$ ika Statistik t hitung $>$ Statistik t tabel, maka Ha ditolak.

J ika probabilitas $>0,05$, maka Haditerima.

J ika probabilitas $<0,05$, maka Haditolak.

- Tabel Variables entered menunjukkan bahwa tidak ada variabel yang dikeluarkan (removed), atau dengan kata lain kedua variabel bebas dimasukkan dalam perhitungan regresi.

- $\quad$ Angka R Square $\left(R^{2)}\right.$ adalah 0,269.

Berarti hanya 26,9\% Kepuasan kerja $\left(Y_{1}\right)$ bisa dipengaruhi (dijelaskan) oleh variabel budaya organisasi $\left(X_{1}\right)$ dan konflik peran $\left(X_{2}\right)$. Sedangkan sisanya sebesar $73,1 \%(100 \%-26,9 \%=73,1 \%)$ dijelaskan oleh sebabsebab atau faktor yang lain.

Catatan: $\mathrm{R}^{2}$ berkisar pada angka 0 sampai 1 , (semakin kecil angka $\mathrm{R}$ square, semakin lemah hubungan kedua variabel).

- Dari uji ANOVA atau F test, didapat F hitung adal ah sebesar 9,007 dengan tingkat signifikansinya sebesar 0,0000 . Karena probabilitas $(0,000)$ jauh lebih kecil dari 0,05, maka model regresi ini bisa dipakai untuk memprediksi variabel kepuasan kerja $\left(\mathrm{Y}_{1}\right)$. Atau bisa dikatakan, variabel Budaya organisasi $\left(X_{1}\right)$ dan variabel konflik peran secara bersama-bersama berpengaruh terhadap kepuasan kerja $\left(\mathrm{Y}_{1}\right)$.

\begin{tabular}{ccccc}
\hline Hipotesis & $\begin{array}{c}\text { Variabel } \\
\text { Dependent }\end{array}$ & Nilai t & Nilai Signifikansi & Status \\
\hline $\mathrm{H} 2 \mathrm{a}$ & $\mathrm{X} 1$ & 1,246 & 0,219 & Diterima \\
$\mathrm{H} 2 \mathrm{~b}$ & $\mathrm{X} 2$ & 3,868 & 0,000 & Ditolak \\
\hline
\end{tabular}

b. Uji Hipotesa Pada Variabel Dependent $\mathrm{Y}_{2}$ Terhadap Variabel $\mathrm{X}_{1}$, dan $\mathrm{X}_{2}$.

- Tabel Variables entered menunjukkan bahwa tidak ada variabel yang dikeluarkan (removed), atau dengan kata lain kedua variabel bebas dimasukkan dalam perhitungan regresi.

- $\quad$ Angka $R$ Square $\left(R^{2)}\right.$ adalah 0,311.

Berarti hanya 31,1\% Kepuasan kerja $\left(Y_{1}\right)$ bisa dipengaruhi (dijelaskan) ol eh variabel budaya organisasi $\left(X_{1}\right)$ dan konflik peran $\left(X_{2}\right)$. Sedangkan sisanya sebesar $68,9 \%(100 \%-31,1 \%=68,9 \%)$ dijelaskan oleh sebabsebab atau faktor yang lain.

Catatan: $\mathrm{R}^{2}$ berkisar pada angka 0 sampai 1 , (semakin kecil angka $\mathrm{R}$ square, semakin lemah hubungan kedua variabel).

- Dari uji ANOVA atau F test, didapat F hitung adal ah sebesar 11,072 dengan tingkat signifikansinya sebesar 0,0000 . Karena probabilitas $(0,000)$ jauh lebih kecil dari 0,05, maka model regresi ini bisa dipakai untuk memprediksi variabel kepuasan kerja $\left(\mathrm{Y}_{1}\right)$. Atau bisa dikatakan, variabel Budaya organisasi $\left(X_{1}\right)$ dan variabel konflik peran secara bersamabersama berpengaruh terhadap kepuasan $\operatorname{kerja}\left(\mathrm{Y}_{1}\right)$.

\section{Pembahasan}

1. Temuan pada penelitian ini menunjukkan bahwa responden mempertimbangkan Budaya organisasi berbagai faktor yang membentuk kepuasan kerja meliputi lingkungan kerja, factor kebiasaan dalam budaya kerja, upah, promosi, rekan sekerja dan supervisi (Quarstein, 1993 dal am Luthans, 1998) sehingga penilaian kepuasan kerja tidak di dasarkan hanya dari perubahan faktor kerja, 
tetapi mempertimbangkan keseluruhan faktor yang mempengaruhi kepuasan kerja. Secara khusus, responden penelitian ini memiliki tugas berdasarkan profesional itas yang dimili bidang-bidang tertentu atau disebut sebagai beban tugas intitusional dengan komposisi jumlah telah ditetapkan. profesi akuntan, yang menilai ki nerja berdasarkan pencapaian prestasi tertentu. Oleh karena itu, walaupun seorang akuntan merasa puas atau tidak terhadap tugasnya, ancaman negatif berupa pemecatan, tertundanya kenaikan jabatan, atau berkurangnya extrinsic reward kecil kemungkinan untuk terjadi sepanjang terpenuhi beban tugasnya. Sehingga tidak signifikannya pengaruh konflik peran terhadap kepuasan kerja pada penelitian ini dapat dijelaskan. Dengan meli hat hasil uji korelasi yang dilakukan menghasilkan nilai koefisien korelasi yang tinggi $(0,512$ atau $51,2 \%)$ menyebabkan keeratan hubungan budaya organisasi $\left(\mathrm{X}_{1}\right)$ lebih berpengaruh kuat terhadap kepuasan kerja $\left(\mathrm{Y}_{1}\right)$.

2. A pakah konflik peran memberikan pengaruh yang signifikan terhadap komitmen organisasional. Penelitian ini mengindikasikan konflik peran yang terjadi dalam lingkungan professional (seperti Akuntan) di sebabkan seorang akuntan lebih mengedepankan norma-norma, aturan dan kode etik profesi dalam menangani persoalan ditemui dalam tugas, jika dalam tugas di pengaruhi manajemen, seperti penerapan aturan kepegawaian maka dapat memicu timbulnya konflik peran. Hall. (1987).

Begley et. al. (1993) menyatakan bahwa individu yang berkomitmen tinggi cenderung rentan terhadap ancaman perubahan yang berasal dari dalam organisasi tapi sekaligus dapat menahan pengaruh negatif job displeasure seperti konflik peran,dan ambiguitas peran dibandingkan mereka yang tidak berkomitmen. Sikap komitmen organisasi merupakan interaksi faktor demografi seperti faktor usia, masa kerja, dan gender, faktor kepribadian seperti kebutuhan, tipe kepribadian, dan pusat kendali diri-, serta faktor organi sasiseperti desain tugas dan supervisi yang diterima dari pimpinan. Penelitian ini mengindikasikan peran komitmen organisasi berfungsi menahan pengaruh negatif job displesure yang diakibatkan ol eh konflik peran melalui kebijaksanaan organisasi yang berhubungan dengan desain tugas, meliputi otonomi tugas, signifikansi tugas, kejelasan tugas dan kualitas individu. Kebijaksanaan organi sasi berikut ditemukan dapat menghambat job displesure Kebijaksanaan lembaga yang mendukung pendidikan lanjut bagi akuntan bertujuan untuk meningkatkan kualitas akuntan dan stafnya di samping seminar dan kursus. Kebijaksanaan mengikut sertakan para staff akuntan dalam pengambilan keputusan dan penyel esai an masal ah yang berkaitan dengan fungsi dan tugas akuntan berfungsi meningkatkan moral dan performance, serta kebijaksanaan kompensasi secara memadai. Mempertimbangkan pula faktor demografi responden dari usia dan masa kerja yang berperan memperkuat komitmen organisasi melalui penetapan kebijaksanaan organisasi secara memadai.

\section{SIMPULAN}

1. Budaya organisasional memberikan pengaruh yang signifikan terhadap kepuasan kerja. Temuan pada penelitian ini menunjukkan bahwa responden mempertimbangkan Budaya organisasi berbagai faktor yang membentuk kepuasan kerja meliputi lingkungan kerja, factor kebiasaan dalam budaya kerja, upah, promosi, rekan sekerja dan supervisi Quarstein, (1993) dalam Luthans, (1998) sehingga penilaian kepuasan kerja tidak didasarkan hanya dari perubahan faktor kerja, tetapi mempertimbangkan keseluruhan faktor yang mempengaruhi kepuasan kerja. Melihat hasil uji korelasi yang dilakukan menghasilkan nilai koefisien korelasi yang tinggi (0,512 atau 51,2\%) menyebabkan keeratan hubungan budaya organisasi $\left(X_{1}\right)$ lebih berpengaruh kuat terhadap kepuasan kerja $\left(\mathrm{Y}_{1}\right)$ 
Analisis

Budaya

Organisasional

400
2. Konflik peran memberikan pengaruh yang signifikan terhadap komitmen organisasional. Penelitian ini mengindikasikan konflik peran yang terjadi dalam lingkungan professional (seperti Akuntan) disebabkan seorangakuntan lebih mengedepankan norma-norma, aturan dan kode etik profesi dalam menangani persoalan ditemui dalam tugas, jika dalam tugas di pengaruhi manajemen, seperti penerapan aturan kepegawaian maka dapat memicu timbulnya konflik peran. (Hall.1987). Begley et al. (1993) menyatakan bahwa individu yang berkomitmen tinggi cenderung rentan terhadap ancaman perubahan yang berasal dari dalam organisasi tapi sekaligus dapat menahan pengaruh negatif job displeasure seperti konflik peran,dan ambiguitas peran dibandingkan mereka yangtidak berkomitmen. Melihat hasil uji korelasi yang dilakukan menghasilkan nilai koefisien korelasi yang tinggi (0,538 atau 53,8 \%), keeratan hubungan konflik peran $\left(\mathrm{X}_{2}\right)$ lebih berpengaruh kuat terhadap komitmen organisasi $\left(\mathrm{Y}_{2}\right)$.

\section{Keterbatasan Penelitian.}

Hasil penelitian ilmiah senantiasa harus dikembangkan. Penelitian lanjutan perlu dilakukam karena penelitian ini mempunyai beberapa keterbatasan yaitu:

a) J umlah sampel yang diambil amat kecil seharusnya sampel yang diambil minimum 100 responden ini dikarenakan terbatasnya waktu pengirirman dan terlambatnya pengembalian isian kuisioner yang kami sebarkan pada responden di Indonesia bagian tengah dan Indonesia bagian timur,

b) Alat analisis penelitian mini ini merupakan hasil regresi berganda yang sederhana dari Program SPSS Ver.12, dengan tidak mengecilkan arti dari penelitian ini, peneliti sadar seharusnya mengolah data dengan al at anal isis yang menggunakan program pengolah AMOS tetapi dikarenakan samplekuisioner yang ada hanya 52 seharusnya dibutuhkan 100 responden maka peneliti menggunakan regresi berganda yang sedikit banyak ada kelemahan-kelemahan yang tidak terdeteksi oleh penel iti.kesalahan dal am construct penelitian, menentukkan alat analisa dan model dari analisa tersebut.

\section{Saran-Saran}

Hasil penelitian ini diharapkan dapat memberikan kontribusi pada pengembangan teori, terutama yang berkaitan dengan akuntansi keprilakuan. Penelitian ini juga diharapkan dapat memberikan kontribusi praktis untuk organisasi terutama Kantor A kuntan Publik (KAP) dal am mengel ol a sumber daya manusianya. Seperti telah disebutkan penelitian ini merupakan penel itian replikasi, Hasil studi Kozlowski dan Doherty (1989) yang dikutip dari studi O'Driscoll dan Beehr (1994) menunjukkan bahwa bagian dari el emen organisasi di KAP yaitu supervisor merupakan pihak yang paling dekat dengan konteks kerja seseorang karena melalui mereka tercermin budaya dan iklim organisasi .

\section{DAFTAR PUSTAKA}

Aranya, N dan K. Ferris, 1994. "A re examination of accountan organizational profesional conflict". The Accounting Review 59 (J anuary): 1-15

Bateman, T dan S. Strasser, 1984. "A Iongitudinal analysis of the antecedents of theantecedent of organizational commitment". Academy of Management J ournal 27: 95-112

Bamber, E Michael., Snowball, Doug., Tubbs, Richard M. 1989. “Audit Structure and its Relation to Role Conflict and RoleAmbiquity: An E mpirical I nvestigation". The Accounting Review. Vol. LXIV, N o.2. pp. 285-299

Begley, M. Thomas \& J oseph M. Czajka. 1993. Panel Analysis of The M oderating Effects of Commitement on J ob satisfaction, Intent to Quit, and Health F ollowing Organizational Change, J ournal of Applied Psychology 
Davis, Kieth, 1995. Human Behavior at Work: Organizational Behavior. Mc. Graw Hill Publishing Compony, New Del hi.

Dunham, J. B., G. L. Vinyard, and B. E. Rieman. 1997. Habitat fragmentation and extinction risk of Lahontan cutthroat trout. North American J ournal of Fisheries Management. 17:1126-1133.

Fitria Puspa D., Riyanto B.LS. 1999. “Tipe lingkungan Pengendalian Organisasi, Orientasi Profesional, Konflik Peran, Kepuasan Kerja, dan Kinerja: Suatu Penelitian Empiris". J urnal Riset Akuntansi Indonesia. Vol. 2, No.1. pp. 117135.

Gregson.T. 1992. "An Investigation of the causal orderimg of job satisfaction and organizational commitment in turnover models in accounting" Behavior Research In Accounting. 4: 80 - 95.

Hall, R.H.1987. Organization: Structure, Processes and Outcomes, Edition 4, Englewood Cliffs N.J . Prentice Hall.

Huck, S.W., dan Cormier, W.H., 1996, "Reading Statistics and Research", 2 ${ }^{\text {rd }}$ Ed., NY: Harper Chollins Publichers Inc.

H ofstede, Geert. 1990. Motivation, Leadership, and Organization: Do American Theories A pply A broad?. Organizational Dynamics (Summer 1980b): 42-63

J ackson, SE dan R.S. Shuler. 1985. A Meta-analysis and Conceptual Critique of Research on Role Ambiguity and Role Conflict in world Setinggs. Organizational Behavior and Human Decision Process. pp. 16.78

Kahn, D, Wolfe, D, Qiunn, R, Snock, J dan Rosenthal, R.1964. Organizational Stress: Studies in Role Conflict and Ambiguity. New York

Kozl owski, S dan Doherty,M 1989 I ntegration of climateand leadership: Examination of neglected issue. J ournal of Applied Psychology, 74: 546-553.

Kotter, \& Heskett. 1992. Corporate Cultures and Performance. Canada: Maxwell Macmillan

Luthans, Fred. 1998. Organizational Behavior: Personality and Attitudes, Eight Edition, Mc Graw Hill I nternational Edition.

Mangkunergara, A.A.A. Prabu,2000. Manajemen Sumber Daya Manusia Perusahaan. PT. Rosda Karya Bandung.

Mathieu, J . 1991, A. cross level nonrecursive model of the antecedents of organizational commitment and satisfaction. J ournal of Applied Psychol ogy 76 (5): 607618.

Mathieu, J .E., \& Zajac, D.M. 1990, A Review and Meta Analysis of The Antecedents, Correlates and Consequences of Organizational Commitment, Psychological Bulletin.

Mowday, RT.,R.M. Steers., \& L.W.Porter.1979. "the M easurement of Organizatonal Commitment". J ournal of Vocational behavior. 11. Pp.: 224-247.

Ouchi, W.G.,Wilkins. A.L (1985). Organizational Culture, Annual Review of Sociology. 11: 457-583.

O’Driscoll.M.P dan Beehr. TA. 1994. Supervisor behavior, role stressors and uncertainy as predictor $\mathrm{S}$ of personal outcomes for subordinates.J ournal of Organizational Behavior, 15: 141-155.

Pratt, J amie \& Beailieu, P. 1992. Organizational Culture in Public Accounting, Size and Technology, Rank and Functional Area, Accounting and Organizational Society,17: 140-161.

Porter. L.W.,R.M. Steers., R.T. Mowday., and P.V. Boulin. 1974. “ Organizational commitment, J ob Satisfaction and Turnover Among Psychiatric Technicians" J ournal of Applied Psycology (october).pp.: 603-609

Poznanski, Peter, J . Bline, M. Dennis. 1997. Using structural equation modeling to investigate the causal ordering of job satisfaction and organization commitment among staff accountants. Behavioral Research in Accounting. Volume 9, 1997. Printed in USA. 
Analisis

Budaya

Organisasional

402
Reynolds, P.O. (1986). Organizational culture as related to industry, position and performance: A preliminary report. J ournal of Management Studies, 23, 333345.

Riggio, R.E, 1990. Introduction to Industrial Organizational Psychology, Glenview, Illinois: Scott, For esman. LittleBrown Higher E ducation.

Rizzo, J R., House, \& Lirtzman. 1970. "Role Conflict and Ambiquity in Complex Organizations." dalam Comerford, Sue E, Abernethy, Margaret A. 1999. Behavioral Research in Accounting, Vol 11. pp.93-110

Suwandi \& Indriantoro. 1999. “M odel Turnover Pasewark \& Strawser: Studi Empiris Pada Lingkungan Akuntansi Publik". J urnal Riset Akuntansi Indonesia. Vol. 2, No.2. pp.173-195.

Scarpello, V., \& Campbell, J . P. (1983). J ob satisfaction: Are all the parts there? Personnel Psychology, 36, 577-600.

Supomo,B dan Indriantoro, Nur. 1998. Pengaruh struktur dan budaya organisasional terhadap keefektifan anggaran partisi patif dalam peningkatan kinerja manjerial. Studi empiris pada perusahaan manufaktur Indonesia. J urnal Kelola No.18NII.

Weiss, Marvin, 1972, “Where 'H uman Resources Accounting'Stands Today”, J ournal Administrative Management, November 1972, pp.43-48.

Mahoney, T. A. T.H J erdee dan S.J . Carroll. (1963), Development of Managerial Performance: A Research Approach.Cincinnati, OH: Southwestern Publishing Co 